\title{
The Asymmetric Catalytic Mannich Reaction Catalyzed by Organocatalyst - A Personal Account -
}

\author{
Yujiro Hayashi* \\ Department of Chemistry, Graduate School of Science, Tohoku University \\ 6-3 Aramaki-Aza Aoba, Aoba-ku, Sendai 980-8578, Japan
}

(Received July 22, 2014; E-mail: yhayashi@m.tohoku.ac.jp)

\begin{abstract}
The Mannich reaction is a synthetically useful method for the construction of nitrogen-containing molecules. Organocatalysts have been successfully applied to the Mannich reaction. Our group has been engaged in research on the organocatalyst-mediated Mannich reaction since the early days of its development in 2002. We have developed a proline-mediated three-component Mannich reaction of aldehyde, ketone and $p$-anisidine under the high pressure induced by water-freezing. Proline was found to effectively promote the cross Mannich reaction of two different aldehydes to afford the Mannich product with syn-selectivity and excellent enantioselectivity, conditions successfully employed as a key reaction for the stereoselective synthesis of the $N$-terminal amino acid moiety of Nikkomycin B and Bx. A trifluoromethyl-substituted diarylprolinol silyl ether is an effective organocatalyst of the Mannich reaction with acetaldehyde as nucleophile. It is also effective in the desulfonylative Mannich reaction of aliphatic aldehyde, $\alpha$-chloroacetaldehyde and $\alpha$-keto aldehyde which are employed as a precursor of the imine, affording the desired Mannich products with antiselectivity and excellent enantioselectivity. As the obtained Mannich products are useful chiral building blocks which can be prepared by this simple procedure, the present methods are important for the synthesis of nitrogen-containing molecules.
\end{abstract}

\section{Introduction}

The field of organocatalysis ${ }^{1}$ has been developing very rapidly since the discovery of the proline-mediated intermolecular asymmetric aldol reaction in 2000 by List, Lerner and Barbas. $^{2}$ Organocatalysts are particularly synthetically useful because of the following merits. 1) As reactions with organocatalyst are not greatly affected by oxygen or moisture, they need not be carried out under strictly oxygen-free and anhydrous conditions. 2) As no metal is employed, there is no concern that it might contaminate the product. Many kinds of organocatalysts with unique properties have been developed, and many kinds of reactions have been reported to proceed with excellent enantioselectivity catalyzed by organocatalyst. Our group has been investigating such reactions, and has already reported several effective organocatalysts and synthetically useful reactions using them. We also have an interest in the application of organocatalyst-mediated reactions to the efficient total synthesis of biologically-active compounds. In this review I will describe my personal endeavors to develop the Mannich reaction catalyzed by organocatalyst.

The catalytic, asymmetric Mannich reaction is one of the most powerful methods for the construction of chiral nitrogen-containing molecules. ${ }^{3}$ When we started to investigate the asymmetric Mannich reaction in early 2000, several excellent results had already been reported, some of which are based on catalytic asymmetric additions of a pre-formed enolate to aldimines. ${ }^{4}$ Unlike such Mannich reactions of pre-formed enolates, the research groups of Shibasaki, ${ }^{5}$ Jørgensen, ${ }^{6}$ and Trost $^{7}$ have developed direct, catalytic asymmetric Mannich reactions using chiral organometallic catalysts.

On the other hand, after the discovery of the prolinemediated aldol reaction in $2000^{2}$ mentioned above, organocatalysts began to be applied to other reactions including the Mannich reaction. In the same year as the seminal proline-medi- ated aldol reaction, List developed a three-component, asymmetric Mannich reaction of an aldehyde, 4-methoxyaniline ( $p$-anisidine), and a ketone (eq. 1$),{ }^{8}$ while Barbas and coworkers reported a Mannich reaction of $N$-PMP-protected $\alpha$-imino ethyl glyoxylate and an aldehyde and ketone in 2002 (eq. 2). ${ }^{9}$ As the direct asymmetric Mannich reaction is synthetically important for the synthesis of nitrogen-containing chiral molecules, our group has had an interest in applying organocatalysts to such reactions since 2002. First, I would like to describe why I came to be involved with organocatalytic reactions.
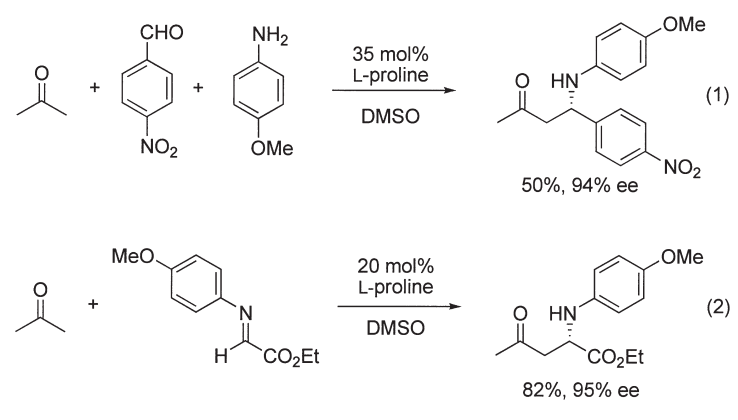

\section{Personal Background}

When I started my independent career in 1998, I had an interest in high-pressure chemistry, because this is one of the factors that can effectively accelerate many organic transformations, ${ }^{10}$ although its use in organic synthesis is rather limited owing to the necessity for special high-pressure apparatus. I thought that a new and easy method for the generation of high pressure for use in synthetic organic chemistry was necessary. I wanted to develop a high-pressure apparatus which can be used in an ordinary chemistry laboratory. My idea was to use the high pressure generated when water becomes ice: It is well known that a bottle of water will break if left in a refrigerator 
(Figure 1), because the volume of water increases about 10\% on freezing. A high pressure of up to $200 \mathrm{MPa}$ would be generated when water is frozen in a sealed autoclave according to the phase-diagram of water and ice (Figure 2). This high pressure has been elegantly utilized for the inactivation of microorganisms by Hayakawa et al. ${ }^{11}$ I would like to use this high pressure induced by water-freezing in organic synthesis, and in fact we successfully applied it to the proline-mediated aldol reaction, ${ }^{12}$ the Michael reaction of alcohols with $\alpha, \beta$-enones, ${ }^{13}$ and the Baylis-Hillmann reaction. ${ }^{14}$ During the application of this method, we happened to find that an excellent result was obtained when the proline-mediated Mannich reaction was performed under water-freezing high pressure conditions.
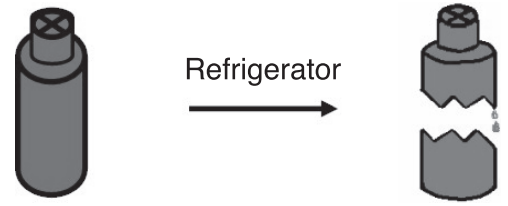

Water

Figure 1. Water freezes into ice.

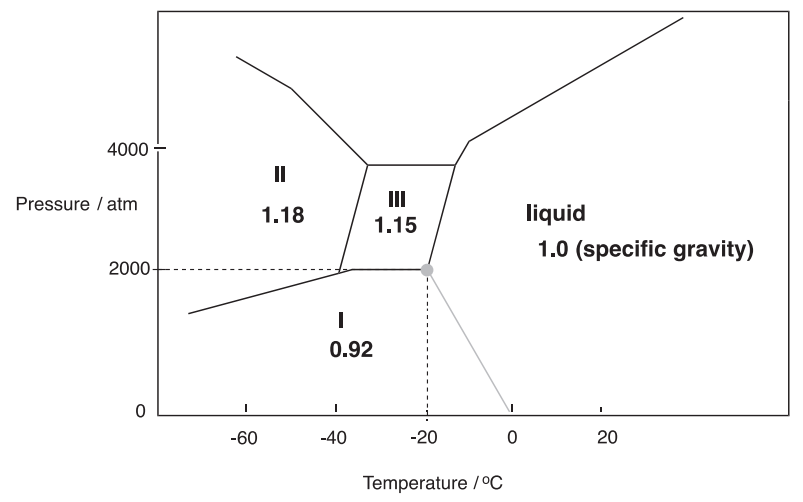

Figure 2. Phase diagram of water.

\section{The Mannich Reaction under High Pressure Induced by Water-freezing ${ }^{15}$}

List reported the proline-mediated three-component Mannich reaction in 2000 (eq. 1). ${ }^{8}$ Although this is an excellent reaction, it does have limitations: Yields are generally insufficient when acetone is used as the Mannich donor, while the Mannich acceptor should be electron-deficient and highly reactive. One of the easy ways to increase the yield is to perform the reaction at higher temperature. But in that case, enantioselectivity would decrease. I applied my water-freezing high pressure method to this reaction, in the expectation that the effects of both high pressure and low temperature would play pivotal roles; i.e. that the yield would be improved due to the negative activation volume of the three-component coupling reaction, and enantioselectivity would be improved because the reaction would proceed at lower temperature $\left(-20{ }^{\circ} \mathrm{C}\right)$ than List's condition of room temperature.

The Mannich reaction of $p$-bromobenzaldehyde, $p$-anisidine, and acetone was investigated under high-pressure induced by water-freezing, and it was found that the Mannich and aldol adducts were obtained in 57\% yield with $95 \%$ ee, and in $11 \%$ yield with $78 \%$ ee, respectively. When the same reaction was performed under ambient pressure at room temperature, the reaction proceeded slowly, affording the Mannich adduct in $25 \%$ yield with $88 \%$ ee, the aldol product in $10 \%$ yield with $74 \%$ ee, and 4-( $p$-bromophenyl)-3-butene-2-one, the dehydrated product, in $12 \%$ yield (eq. 3 ). As expected, better yield and enantioselectivity were obtained when the reaction was conducted under high-pressure induced by water-freezing.

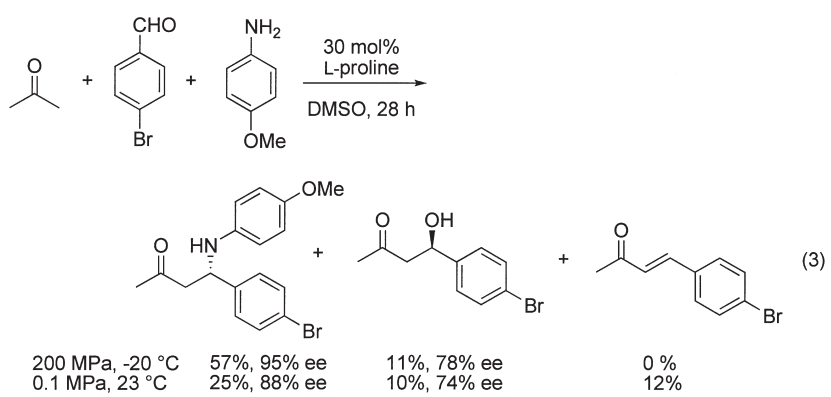

This high pressure method widens the scope and generality of the Mannich reaction (Table 1). High pressure and low temperature are both essential for the success of this asymmetric catalytic reaction; the former not only accelerates the reaction but also suppresses side reactions such as the formation of $\alpha, \beta$-enone. An especially noteworthy feature is that electron-rich, aromatic aldehydes, unreactive substrates under ambient pressure, can be successfully employed, affording the product in good yield.

Table 1. Generality of the Mannich reaction under high pressure induced by water-freezing.

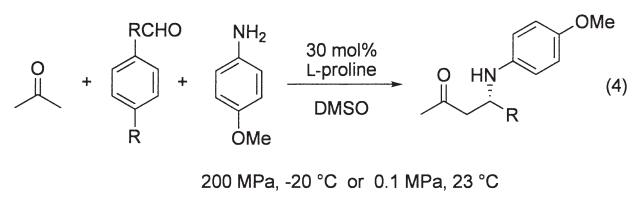

\begin{tabular}{llll|ll}
\hline \multirow{2}{*}{ Entry } & Aldehyde & \multicolumn{2}{l|}{$0.1 \mathrm{PMa}, \mathrm{rt}$} & \multicolumn{2}{l}{$200 \mathrm{Mpa},-20{ }^{\circ} \mathrm{C}$} \\
& & Yield/\% & Ee/\% & Yield/\% & Ee/\% \\
\hline 1 & $p$-nitrobenzaldehyde & 63 & 69 & 75 & 75 \\
2 & $o$ chlorobenzaldehyde & 95 & 65 & 96 & 70 \\
3 & benzaldehyde & 62 & 69 & 78 & 75 \\
4 & 1-naphthaldehyde & 14 & 86 & 67 & 93 \\
5 & $p$-anisaldehyde & 31 & 59 & 30 & 76 \\
6 & 3,4-dimethoxybenzaldehyde & 0 & & 65 & 95 \\
7 & $N$-acetyl-(4-formyl)aniline & 0 & & 82 & 92 \\
8 & 2-furaldehyde & 65 & 95 & 95 & $>99$ \\
9 & cyclohexylcarbaldehyde & 23 & 4 & 90 & 84 \\
\hline
\end{tabular}

\section{The Cross-Mannich Reaction of Two Different Aldehydes ${ }^{16,17}$}

During the application of high pressure induced by waterfreezing, we found that the cross-Mannich reaction of two different aldehydes can proceed efficiently at ambient pressure, which is synthetically very useful. When we started to investigate the Mannich reaction, cross-Mannich reaction of aldehyde had already been reported only for $N$-PMP-protected $\alpha-$ imino ethyl glyoxylate, which is a very reactive Mannich acceptor (eq. 5). ${ }^{9}$ Cross-Mannich reaction of other aldehydes as the electrophilic partner was unknown. The problem with the cross-Mannich reaction is side reactions such as the crossaldol reaction catalyzed by proline.

We found this side reaction can be suppressed by choosing 


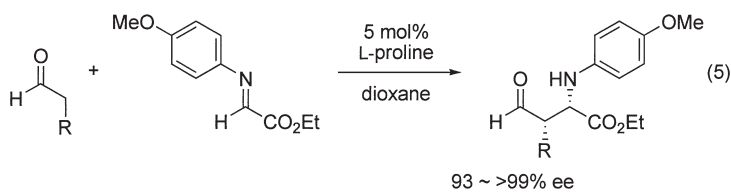

a suitable temperature: We selected the three-component Mannich reaction of propanal, $p$-anisidine and benzaldehyde as a model reaction. First, $p$-anisidine and benzaldehyde were stirred in the presence of $\mathrm{L}-$ proline, which generates imine. To the same reaction vessel, propanal was added at $-20{ }^{\circ} \mathrm{C}$, after which the reaction proceeds at this temperature to afford Mannich product in good yield with excellent syn-selectivity and enantioselectivity without generation of the aldol product. When the reaction was conducted at higher temperature, aldol product was obtained. The success of this procedure indicates that the aldimine was formed even at $-20{ }^{\circ} \mathrm{C}$, and that the reaction between the aldehyde and aldimine is faster than the self-aldol reaction. Some of our results are summarized in Table 2. The reaction has wide generality. Not only benzaldehyde but also substituted benzaldehydes such as $p$-nitro, $p$-bromo and $p$-chlorobenzaldehydes can be successfully employed. Heteroaromatic aldehydes such as furfural and $p$-pyridinecarbaldehyde gave good results. Not only propanal, but also butanal and pentanal can be employed as the nucleophilic aldehyde.

Table 2. Cross Mannich reaction of aldehyde.

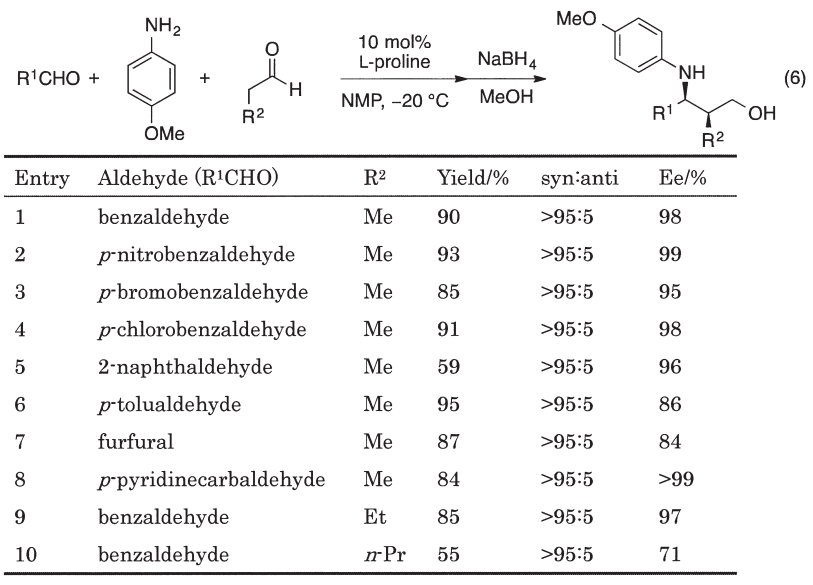

The self-Mannich reaction of propanal also proceeds efficiently (eq. 7). In this reaction, all three components, propanal, $p$-anisidine, and $\mathrm{L}$-proline are mixed together at $-20{ }^{\circ} \mathrm{C}$ without pre-formation of the aldimine.

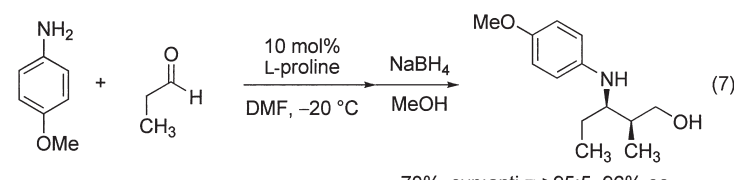

$70 \%$, syn:anti $=>05: 5,06 \%$
Scheme 1. The reaction scheme of the Mannich reaction.

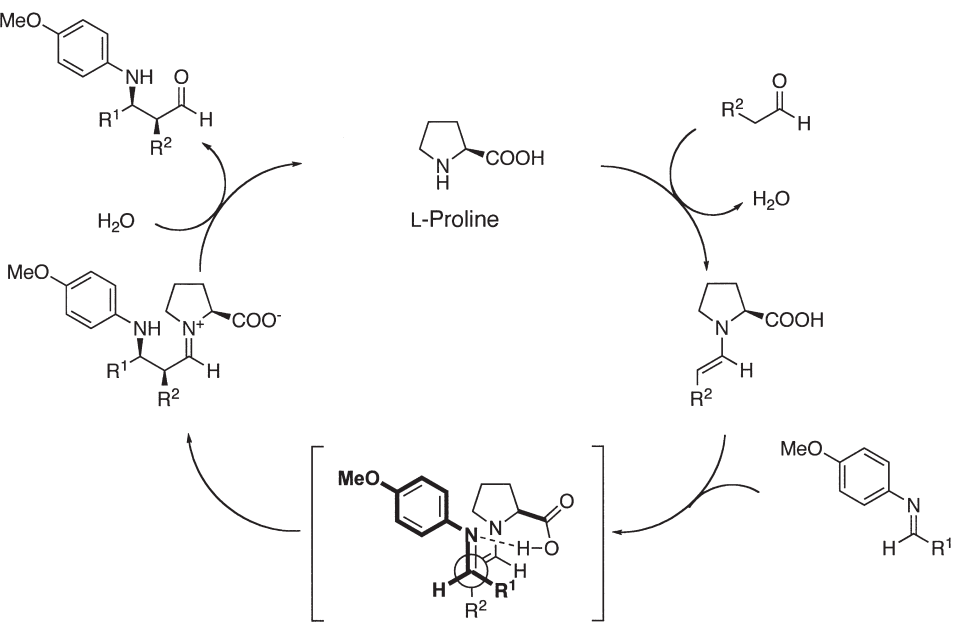

The reaction is presumed to proceed via an enamine intermediate. An imine is generated from aldehyde and $p$-anisidine. An enamine is also formed, this from the second aldehyde and proline. The enamine reacts with the imine via the transition state shown in Scheme 1, in which the proton of the carboxylic moiety coordinates to the imine nitrogen. This transition state model explains why the syn-isomer is obtained predominantly. An iminium ion is generated, which reacts with water to afford the Mannich product and regenerate proline.

\section{The Reactivity Difference between Aldimine versus Aldehyde in the Proline Mediated Mannich Reaction and Aldol Reaction $^{18}$}

The cross-Mannich reaction of two different aldehydes proceeds at $-20{ }^{\circ} \mathrm{C}$, while the corresponding cross-aldol reaction of different aldehydes has been reported to proceed at $4{ }^{\circ} \mathrm{C}$ by Northrup and MacMillan. ${ }^{19}$ These facts indicate that the aldimine is more electrophilic than the parent aldehyde, which is contrary to the generally accepted notion that an aldimine is less reactive toward nucleophilic addition than its parent aldehyde. Thus, we became interested in the relative reactivity of aldimine and aldehyde in the proline-mediated Mannich and aldol reactions.

The reactivity difference between aldimine and aldehyde was investigated by direct in situ comparison (eq. 8). The reaction was performed as follows: Benzaldehyde $(1.0 \mathrm{M})$ and $p-$ anisidine $(0.50 \mathrm{M})$ were stirred in NMP for $2 \mathrm{~h}$ in the presence of L-proline $(0.1 \mathrm{M})$, affording $N$-benzylidene- $p$-anisidine $(0.50 \mathrm{M})$ and benzaldehyde $(0.50 \mathrm{M})$, as checked by ${ }^{1} \mathrm{H}$ NMR. To this mixture was added propanal $(3.0 \mathrm{M})$ at $-20{ }^{\circ} \mathrm{C}$, and the reaction was quenched after a given period of time by the addition of $\mathrm{NaBH}_{4}$ or $\mathrm{LiAlH}_{4}$. Yields of the Mannich and aldol products were determined after isolation of $\beta$-amino alcohol $\mathbf{1}$ and 1,3-diol 2. The results are summarized in Figure 3. From this in situ comparison, $N$-benzylidene- $p$ anisidine is found to be 6.8 times more reactive than benzaldehyde, which is in good agreement with the reactivity difference

$$
2.0 \text { eq. } \quad 1.0 \mathrm{eq} .
$$




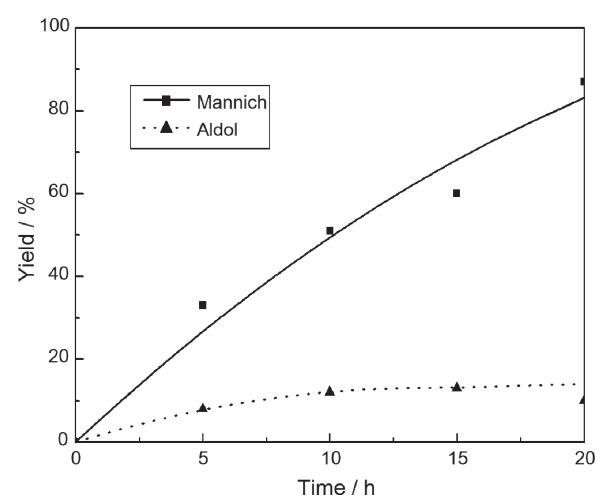

Figure 3. Reactivity difference between proline-mediated Mannich and aldol reactions by direct in situ comparison at $-20{ }^{\circ} \mathrm{C}$.

determined by experiments on the separate electrophilic components.

In order to explain the reactivity difference between aldimine and aldehyde as electrophile, we have calculated energy profiles for the Mannich reaction of $N$-benzylidene- $p$-anisidine and propanal catalyzed by proline, and the aldol reaction of benzaldehyde and propanal catalyzed by proline using density functional theory (B3LYP/6-31G ${ }^{*}$ ) in collaboration with Dr. Uchimaru. It was found that in the Mannich reaction initially protonation occurs on the basic nitrogen of the aldimine, which strongly activates it. This activation is much more effective than the activation by protonation of the less basic aldehyde. As the aldimine is more effectively activated by carboxylic acid protonation than the aldehyde, it is more electrophilic than the aldehyde in proline-mediated reactions.

Moreover, as the proton is mostly transferred to the nitrogen of the imine in the transition state, charge density at the transition state is more localized in the Mannich reaction than in the aldol reaction. Because solvent stabilizes better the more charge-separated transition state, decreasing the activation energy, it is reasonable that the Mannich reaction is faster than the aldol reaction in a polar solvent such as NMP.

To confirm this protonation experimentally, we carried out a ${ }^{1} \mathrm{H}$ and ${ }^{13} \mathrm{C}$ NMR study of aldimine and aldehyde in the presence of acid, which showed that shifts to lower field were observed for the aldimine carbon and hydrogen in accord with the amount of $\mathrm{CF}_{3} \mathrm{CO}_{2} \mathrm{H}$. In the case of the aldehyde however, only small down field shifts were observed. These results clearly indicate that the aldimine is protonated effectively, while the aldehyde is not. The higher reactivity of aldimine over aldehyde is attributed to the effective protonation by acid of the aldimine basic nitrogen, as supported by NMR experiments. In summary, the reason for the higher reactivity of aldimine over aldehyde in the asymmetric, direct, one-pot, three-component, cross-Mannich reaction of two different

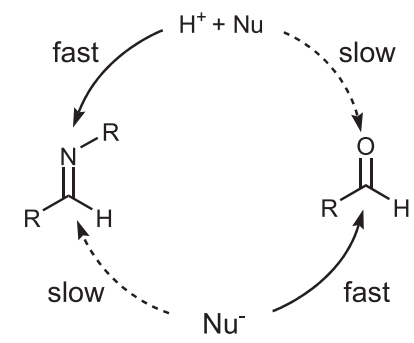

Figure 4. Reactivity difference between aldimine and aldehyde. aldehydes has been experimentally and theoretically investigated with the conclusion that the effective protonation by acid of the aldimine basic nitrogen is the key. The generally accepted notion that aldehyde is more reactive than aldimine is applicable to nucleophilic addition reactions under basic conditions (Figure 4). In the Brønsted acid-mediated reaction, however, aldimine is more reactive than aldehyde.

\section{Synthesis of the $N$-Terminal Amino Acid Moiety of Nikkomycin $\mathbf{B}$ and $\mathbf{B}_{\mathbf{X}}{ }^{20}$}

Nikkomycins $\mathrm{B}$ and $\mathrm{B}_{\mathrm{X}}$ are nucleoside peptide antibiotics isolated from the culture broth of Streptomyces tendae (Figure 5). ${ }^{21}$ They are potent chitin synthetase inhibitors, exhibiting fungicidal, insecticidal, and acaricidal activities. ${ }^{22}$ The nikkomycins can be divided into two structural units, the $C$-terminal nucleoside amino acid and the $N$-terminal amino acid 3. The $N$-terminal amino acid $\mathbf{3}$ and its synthetic equivalent 4 contain the three contiguous stereocenters of an $\alpha-$ methyl $\beta$-amino secondary alcohol moiety, the stereoselective synthesis of which is a synthetic challenge. As an application of the proline-mediated three component cross-Mannich reaction of two different aldehydes, we synthesized this portion of Nikkomycins B and $B_{X}$ (Scheme 2).

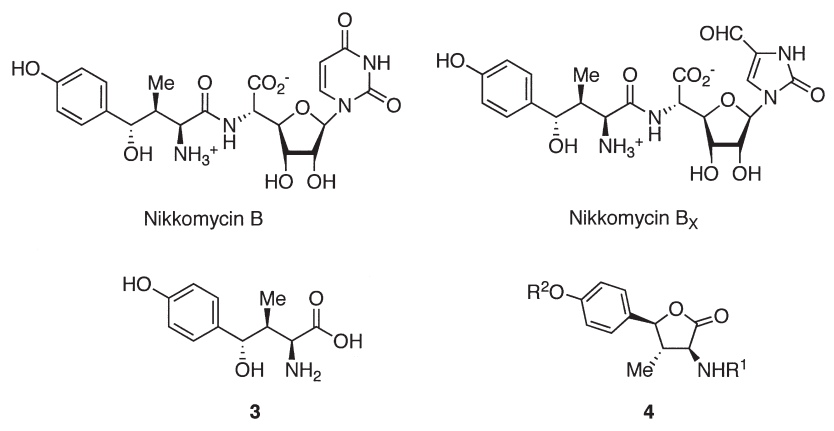

Figure 5. Structure of Nikkomycins $B, B_{x}$ and synthetic intermediates $\mathbf{3}$ and $\mathbf{4}$

The Mannich reaction of 2-furaldehyde, propanal, and 4tert-butyldimethylsiloxyaniline proceeded with high diastereoand enantioselectivities ( $96 \%$ ee). Crude $\beta$-amino aldehyde 5 was immediately treated with $\left(p-\mathrm{MeOC}_{6} \mathrm{H}_{4}\right)_{2} \mathrm{CuMgBr}$ in THF at $-40{ }^{\circ} \mathrm{C}$ to give $\beta$-amino alcohol 6 . The crude mixture of $s y n$ and anti alcohols 6 was oxidized with $\mathrm{SO}_{3} \cdot$ pyridine to afford $\beta$-amino ketone 7 in $70 \%$ yield over three steps. Diastereoselective reduction of $\beta$-amino ketone 7 with $\mathrm{LiAlH}(\mathrm{O}-t-\mathrm{Bu})_{3}$ at $-78{ }^{\circ} \mathrm{C}$ for $1 \mathrm{~h}$ proceeded smoothly, generating $1,2-$ anti alcohol $\mathbf{8}$ in excellent yield and diastereoselectivity ( $98 \%$ yield, 1,2-syn:1,2-anti=1:32).

The hydroxyl and amino groups were protected with the electron-withdrawing benzoyl group by treatment with benzoyl chloride, $\mathrm{Et}_{3} \mathrm{~N}$ and a catalytic amount of DMAP, affording 9 in $61 \%$ yield. The $p$-tert-butyldimethylsiloxyphenyl substituent on nitrogen was successfully removed by successive treatment with TBAF and iodobenzene diacetate in $78 \%$ yield over two steps. Iodobenzene diacetate is a mild oxidant, which allowed the successful removal of the $p$-tert-butyldimethylsiloxyphenyl moiety without affecting the oxidatively-labile $p$ methoxyphenyl group and furan. The reaction of $\mathbf{1 0}$ with sodium periodate and a catalytic amount of ruthenium dioxide $^{23}$ afforded the carboxylic acid, which was treated with diazomethane to afford methyl ester 11 in $47 \%$ yield over two 
Scheme 2. Synthetic scheme for the side chain of Nikkomycins B and $B_{x}$.
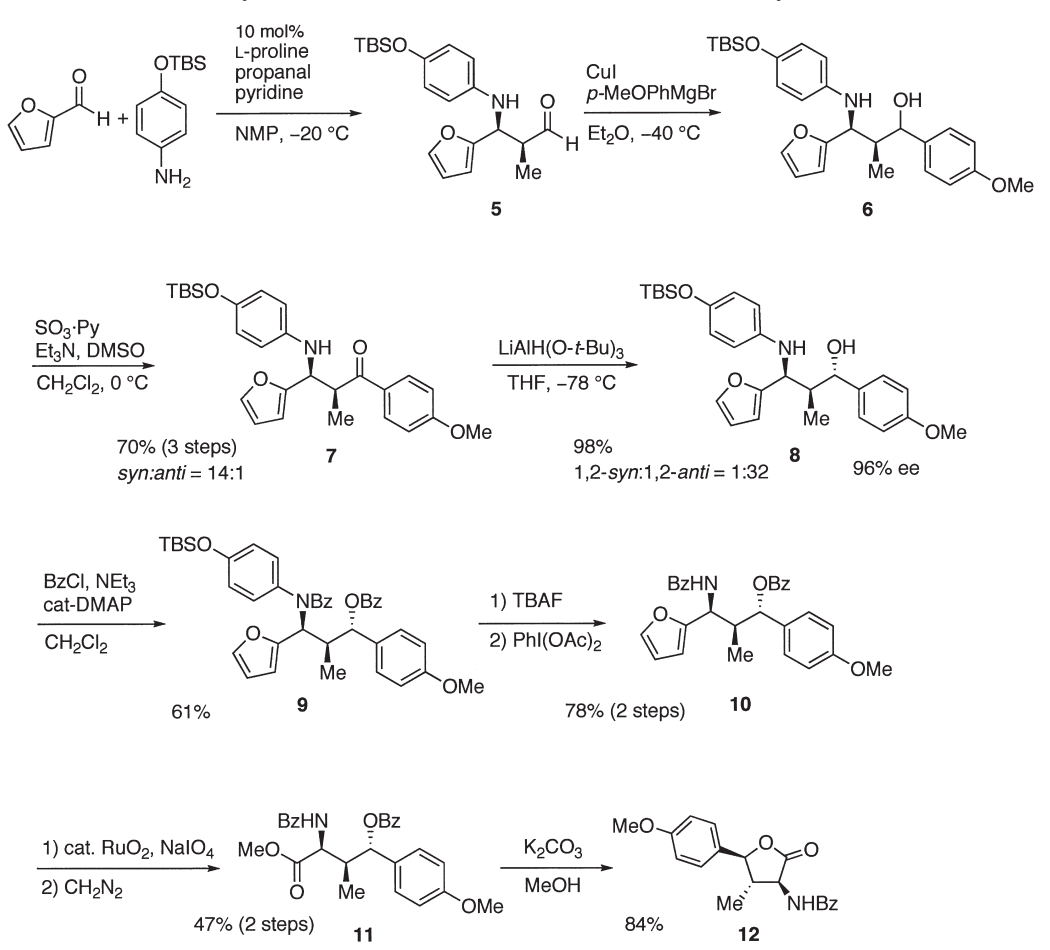

steps. Treatment of $\mathbf{1 1}$ with $\mathrm{K}_{2} \mathrm{CO}_{3}$ in $\mathrm{MeOH}$ gave lactone $\mathbf{1 2}$, identical to the literature product, in $84 \%$ yield. Thus, we were able to construct three contiguous chiral centers and successfully accomplished the formal total synthesis of Nikkomycins $\mathrm{B}$ and $\mathrm{B}_{\mathrm{X}}$.

\section{The Mannich Reaction Using Acetaldehyde as a Mannich Donor $^{24}$}

Controlling the reaction of acetaldehyde has been considered difficult because of its high reactivity both as a nucleophile and as an electrophile, moreover the reaction products, $\alpha$-unsubstituted aldehydes, are equally reactive towards further side reactions. Although silyloxyethene, synthetic equivalents of acetaldehyde, have been developed, ${ }^{25}$ the ability to use acetaldehyde directly as a nucleophile is desirable.
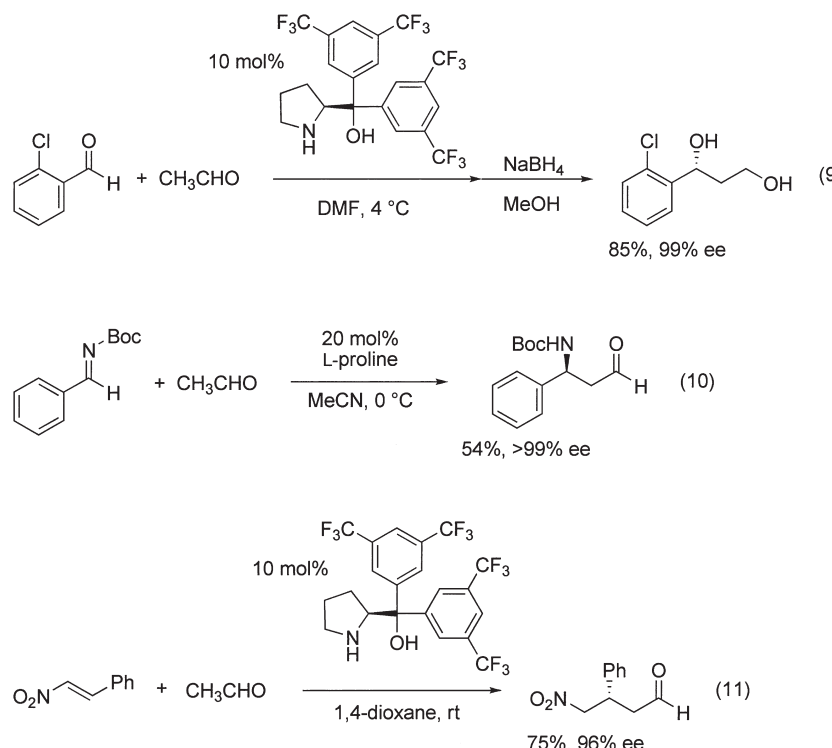

Our group ${ }^{26}$ and List's group ${ }^{27}$ independently developed organocatalyst-mediated asymmetric reactions of acetaldehyde for the first time. We reported a cross-aldol reaction of acetaldehyde catalyzed by trifluoromethyl-substituted diarylprolinol (eq. 9), ${ }^{26}$ whereas List and coworkers reported the proline-catalyzed Mannich reaction of acetaldehyde and $N$-Boc-imine (eq. 10). ${ }^{27}$ At the same time, our group and the List group reported the asymmetric Michael reaction of acetaldehyde and nitroalkene (eq. 11). ${ }^{28,29}$ Shortly after List's Mannich paper, our group also investigated the Mannich reaction of acetaldehyde and $N$ benzoyl-, $N$-Boc- and $N$-Ts-imines catalyzed by the combined use of diarylprolinol silyl ether and $p$-nitrobenzoic acid, which will be explained in this section.

We employed $\mathrm{L}$-proline as a catalyst which is an effective catalyst in the previous cross-Mannich reaction of two different aldehydes. When we used $\mathrm{L}$-proline as a catalyst, the Mannich product was obtained in $51 \%$ yield with $92 \%$ ee. When we performed the reaction under List's conditions using $\mathrm{L}$-proline as a catalyst in $\mathrm{CH}_{3} \mathrm{CN}$, excellent enantioselectivity was obtained with moderate yield. We found that the side reactions are the hydrolysis of the imine and the double Mannich reaction. After screening of the reaction conditions, it was found that diarylprolinol silyl ether, as developed independently by our

Table 3. Mannich reaction of acetaldehyde.

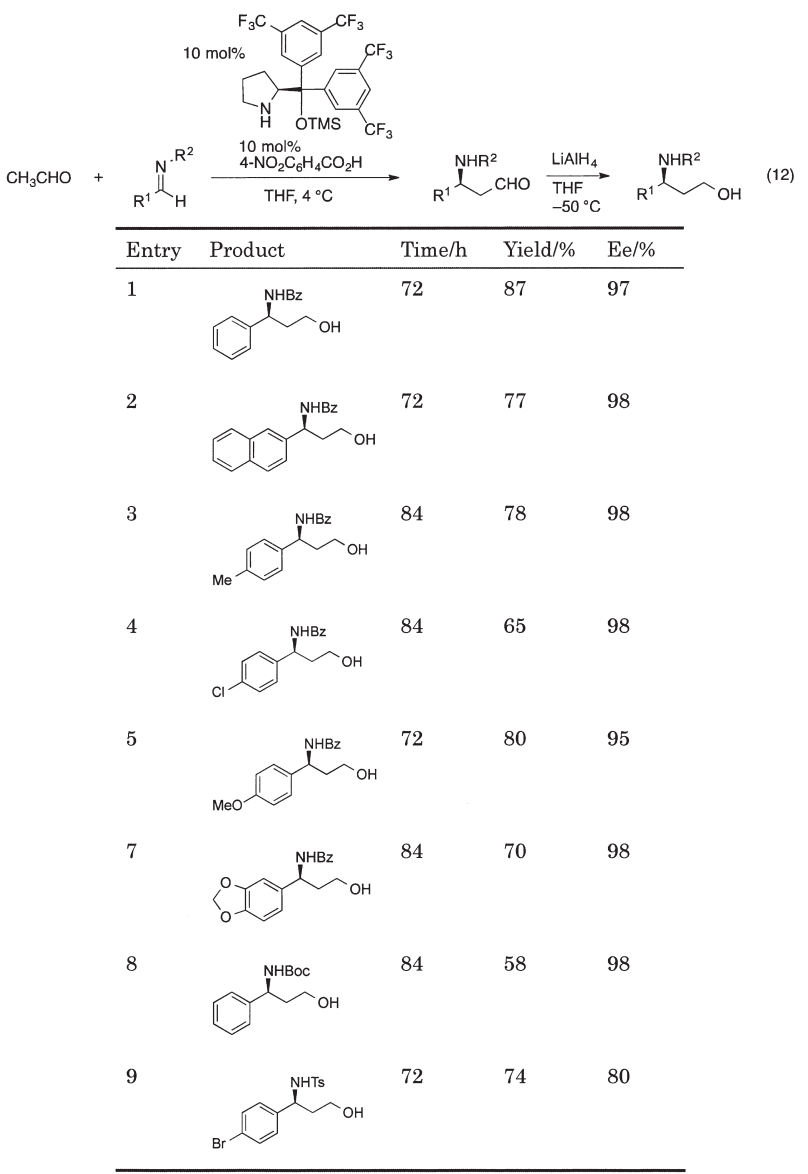


group $^{30}$ and Jørgensen's group ${ }^{31}$, is a catalyst of choice. With the combined use of diarylprolinol silyl ether and $p$ $\mathrm{NO}_{2} \mathrm{C}_{6} \mathrm{H}_{4} \mathrm{CO}_{2} \mathrm{H}$, the Mannich product was obtained in $87 \%$ yield with $97 \%$ ee (Table 3 , entry 1 ). The reaction has some generality (Table 3): It proceeds efficiently for $\mathrm{N}$-benzoylimines derived from electron-deficient arylaldehydes such as $p$-chlorobenzaldehyde and also electron-rich aldehydes such as $p$-anisaldehyde and 3,4-methylenedioxybenzaldehyde. The $N$-benzoyl moiety is known to be removable under several conditions. Moreover, $\mathrm{N}$-Boc-imine and $\mathrm{N}$-Ts-imines are also suitable substrates, providing the Mannich adduct in good yield with excellent enantioselectivity. The present method has several useful features. 1) Catalyst loading (10 $\mathrm{mol} \%)$ is less than the proline-catalyzed version. 2) Suppression of imine decomposition and double Mannich reaction gives improved yields. 3) B3LYP calculation shows that the formation of the enamine is the rate-determining step and that once the enamine forms, it reacts with a protonated imine with no activation barrier.

\section{The Mannich Reaction of Imines Derived from an Aliphatic aldehyde $^{32}$}

Most of the known Mannich reactions are restricted to imines derived from aromatic aldehydes or ethyl glyoxylate, which do not possess a hydrogen at the $\alpha$-position of the formyl group. The catalytic asymmetric cross Mannich reaction of imines derived from alkyl aldehydes with $\alpha$-hydrogens has been regarded as challenging, because of the imines easy isomerization to the corresponding enamines (eq. 13). As imines derived from aliphatic aldehydes are unstable, the domino reaction consisting of the desulfonylative preparation of $\mathrm{N}$-Ts imine and then enantioselective Mannich reaction was investigated.

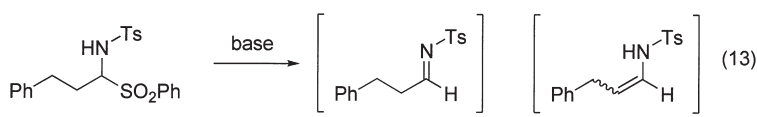

It had previously been reported that the domino reaction of desulfonylative imine formation from 2-[(alkoxycarbonyl)amino]acetate and subsequent Mannich reaction catalyzed by diphenylprolinol silyl ether affords anti-selective $\beta$-amino aldehydes in good yield with good diastereo- and enantioselectivities (eq. 14). ${ }^{33}$ We applied this domino process to aliphatic aldehydes.

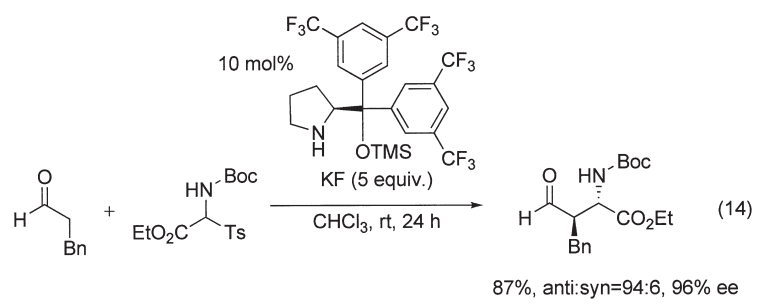

Sulfonamidosulfone was treated with base, catalyst and nucleophilic aldehyde. After some experimentation, we found that an asymmetric Mannich reaction catalyzed by diarylprolinol silyl ether affords the anti-Mannich product with excellent enantioselectivity. Not only organic solvents such as dioxane gave a good result but also brine is a suitable solvent to provide the Mannich product in good yield with excellent selectivity. It is noteworthy that the reaction proceeds in brine without using any organic solvent at all. As for the scope of imines derived from aliphatic aldehydes, not only 3-phenylpropanal but also isovaleraldehyde, isobutyraldehyde, cyclohexanecarbaldehyde, phenylacetaldehyde and benzyloxyacetaldehyde were all suitable for reaction with propanal to afford the Mannich products in good yield with good anti-selectivity and excellent enantioselectivity (Table 4). The reaction proceeds not only with $N$-Ts imines but also with $N$-Ns (nosyl) ${ }^{34}$ imines.

Table 4. Mannich reaction of imine derived from alkyl aldehyde.

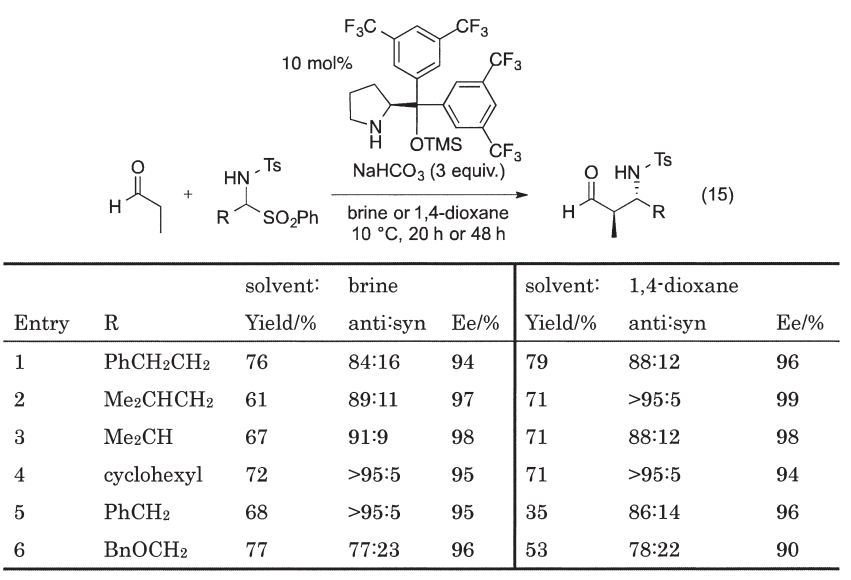

This reaction was found to be applicable to imines derived from aromatic aldehydes. Whereas the precursor of the $N$-Ts imine, $p$-toluenesulfonamido sulfone, derived from an aromatic aldehyde is rather unstable, the corresponding $N$-Ts imine is more stable and could be isolated. Thus, the isolated $N$-Ts imine was used as starting material. The reaction of propanal and $N$-Ts-imine derived from benzaldehyde in the presence of $10 \mathrm{~mol} \%$ of diarylprolinol silyl ether catalyst proceeded well to afford the Mannich product in good yield with good diastereo- and enantioselectivities (eq. 16).

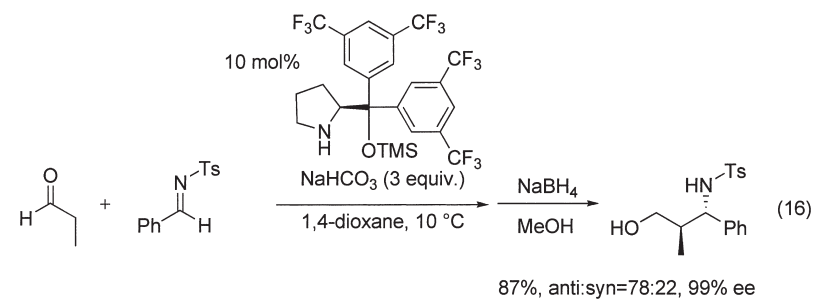

There are several noteworthy features associated with this reaction. 1) This is one of the rare examples of the successful catalytic asymmetric cross-Mannich reaction of an unmodified aldehyde as a Mannich donor and an imine derived from an aliphatic aldehyde with $\alpha$-hydrogens as a Mannich acceptor. 2) The present reaction can be successfully applied not only to imines derived from aliphatic aldehydes but also to imines from aromatic aldehydes. 3) Both $N$-Ts imines and $N$ Ns imines can be used. 4) In the reaction of imines derived from aliphatic aldehydes, brine, without organic solvent, was used as the reaction medium-this offers green reaction conditions. 5) In this reaction using diarylprolinol silyl ether the anti isomer is obtained predominantly, which is in marked contrast to the syn selective Mannich reaction catalyzed by proline. 


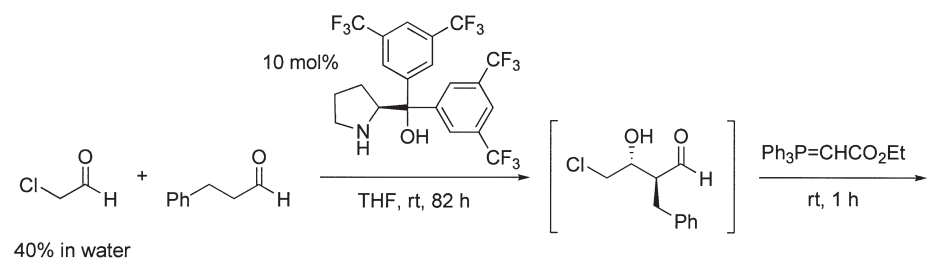

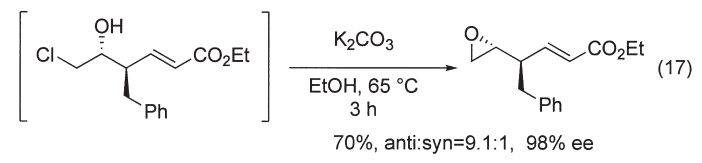

\section{Mannich Reaction of the $N$-Tosyl Imine of Chloroacetaldehyde ${ }^{35}$}

We have reported the one-pot synthesis of chiral $\beta, \gamma-$ epoxyaldehyde via the uninterrupted reaction sequence of an asymmetric aldol reaction of chloroacetaldehyde catalyzed by trifluoromethyl-substituted diarylprolinol, followed by the Wittig reaction and an epoxidation reaction (eq. 17). ${ }^{36}$

We had already found that the asymmetric catalytic Mannich reaction of imines derived from aliphatic aldehydes with $\alpha$-hydrogens is catalyzed by diarylprolinol silyl ether as described in the previous section. Based on these reactions, we designed a synthesis of chiral aziridines via a one-pot procedure as follows: If the asymmetric Mannich reaction of an imine derived from $\alpha$-chloroacetaldehyde proceeds and is followed by an intramolecular nucleophilic substitution, then a chiral aziridine derivative would be generated (eq. 18). Thus, we decided to investigate this possible one-pot synthesis of chiral aziridines.

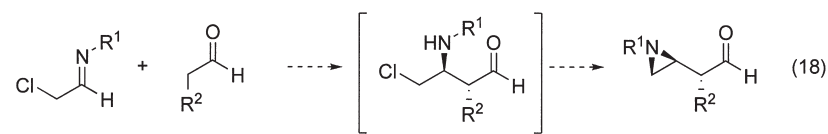

First, we chose as imine $N$-(2-chloroethylidene $)-p$-toluenesulfonamide which can be obtained from $N$-(2-chloro-1phenylsulfonylethyl) $-p$-toluenesulfonamide by treatment with base. However all our attempts to isolate the desired imine were unsuccessful as a result of its rapid degradation. Next we investigated the domino reaction of in situ desulfonylative generation of $\mathrm{N}$-Ts imine followed by enantioselective Mannich reaction. ${ }^{33}$ It was found that trifluoromethyl-substituted diarylprolinol silyl ether is an effective organocatalyst. When diarylprolinol silyl ether, $\mathrm{NaHCO}_{3}, \alpha$-amidosulfone and aldehyde were all mixed together in 1,4 -dioxane at $0{ }^{\circ} \mathrm{C}$, the reaction was found to proceed to provide the desired Mannich product in good yield with excellent anti-selectivity and enantioselectivity. On reaction of the Mannich product with $\mathrm{NaBH}_{4}$, not only did reduction of the aldehyde to alcohol proceed, but also the aziridination reaction occurred to provide the chiral aziridine with excellent enantioselectivity. Uninter-
Table 5. The asymmetric one-pot synthesis of 2-hydroxyethylaziridine.

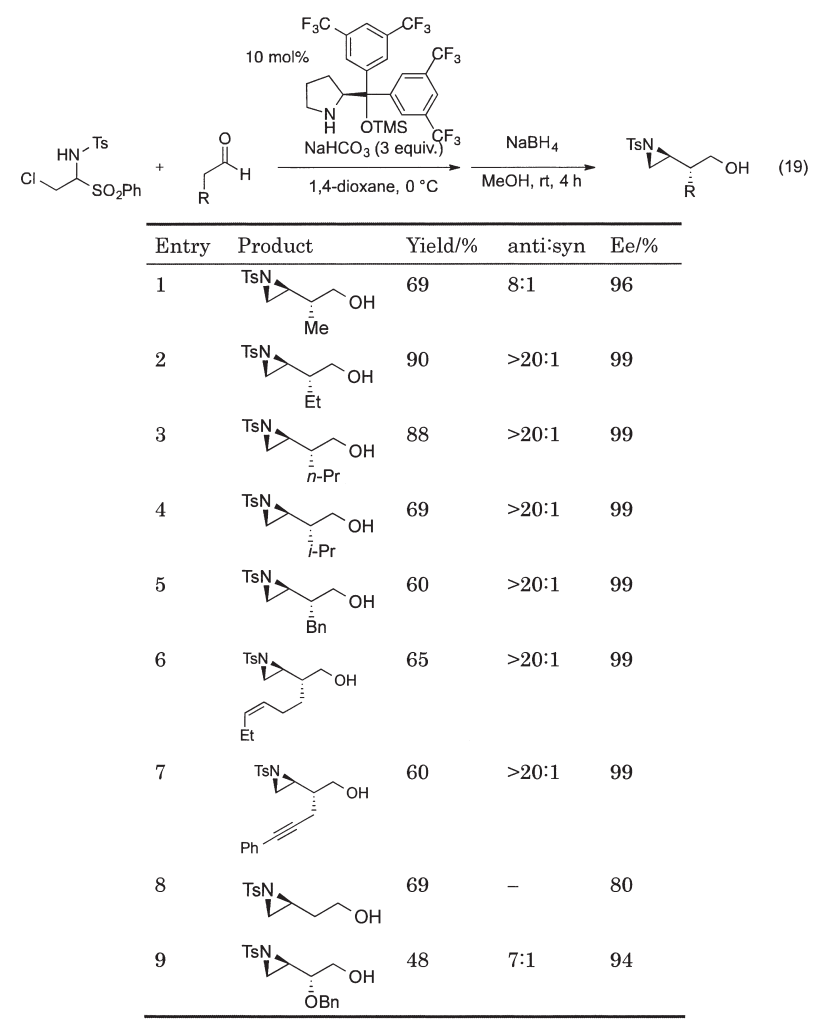

rupted sequential reaction is also possible to provide the chiral aziridine in a one-pot operation, and there is some generality to this reaction (Table 5). Not only propanal, but also other alkyl aldehydes such as butanal, pentanal, isovaleraldehyde, and 3-phenylpropanal can be employed. Double and triple bonds do not affect the reaction. Acetaldehyde and $\alpha$-alkoxyacetaldehyde are also good nucleophilic aldehydes. Ethyl 4aziridinyl-2-pentenoate and aziridine dimethylacetal derivatives can be synthesized in one-pot reactions (eq. 20,21).

\section{The Mannich Reaction of $\alpha$-Keto Imines ${ }^{37}$}

$\alpha$-Amino ketones are useful synthetic intermediates

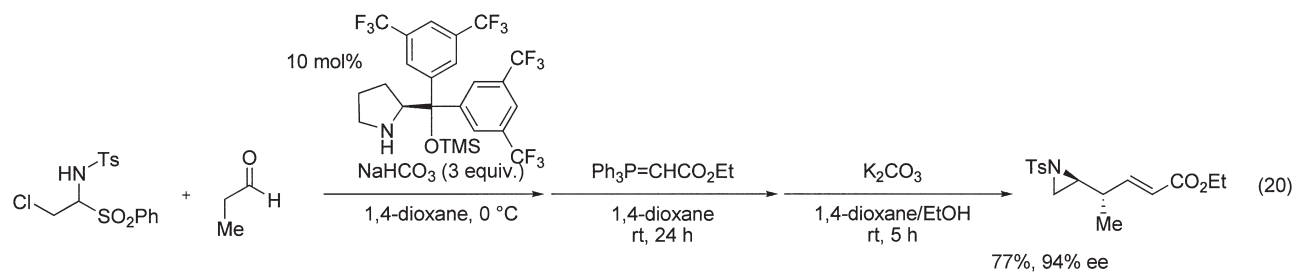



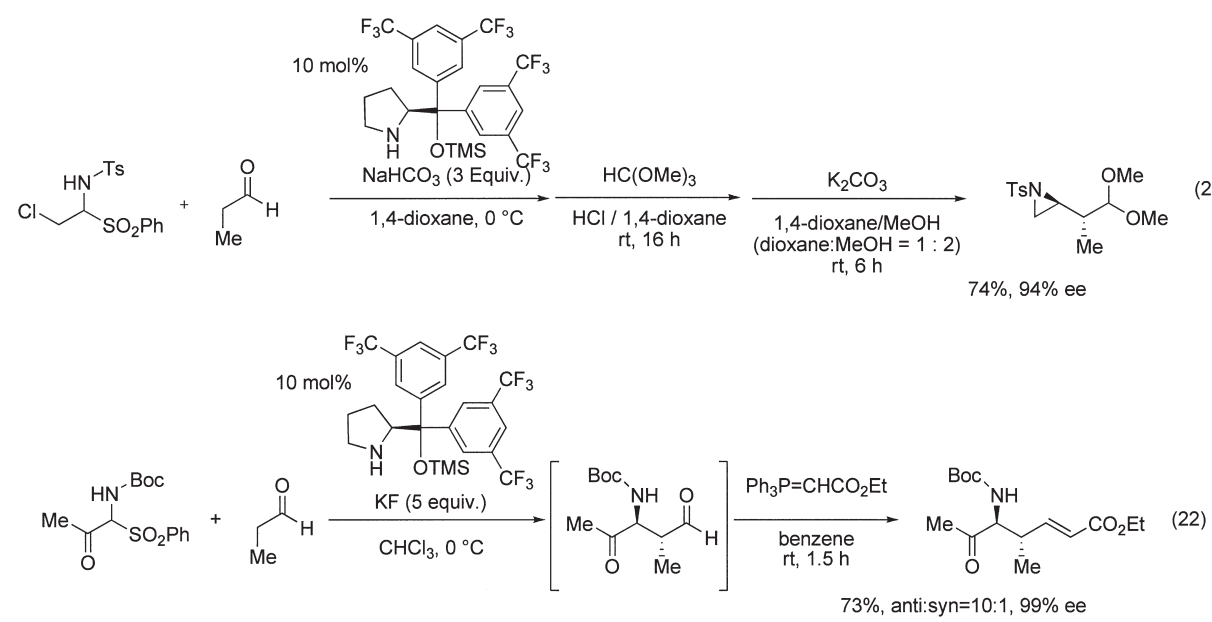

because they can be reduced to give $\alpha$-amino alcohols, and new carbon-carbon bonds can be formed via an aldol reaction with the ketone group. If the Mannich reaction of an $\alpha$-keto imine were to proceed, a $\gamma$-oxo- $\beta$-amino aldehyde would be generated via formation of a new carbon-carbon bond. Because $N$-para-methoxyphenyl (PMP) protected $\alpha$-imino ethyl glyoxylate has been successfully employed in the prolinecatalyzed Mannich reaction (eq. 5), we anticipated that a similar reaction of the PMP $N$-protected imine derived from pyruvaldehyde would also be catalyzed by proline. However, preparation of this imine was found to be difficult under several conditions, and therefore, the Mannich reaction of an $\mathrm{N}^{-}$ Boc imine generated from the corresponding sulfone derivative in situ was investigated. Desulfonylative Mannich reaction was found to proceed catalyzed by trifluoromethyl-substituted

Table 6. The Mannich reaction of imine derived from $\alpha$-ketoaldehyde.

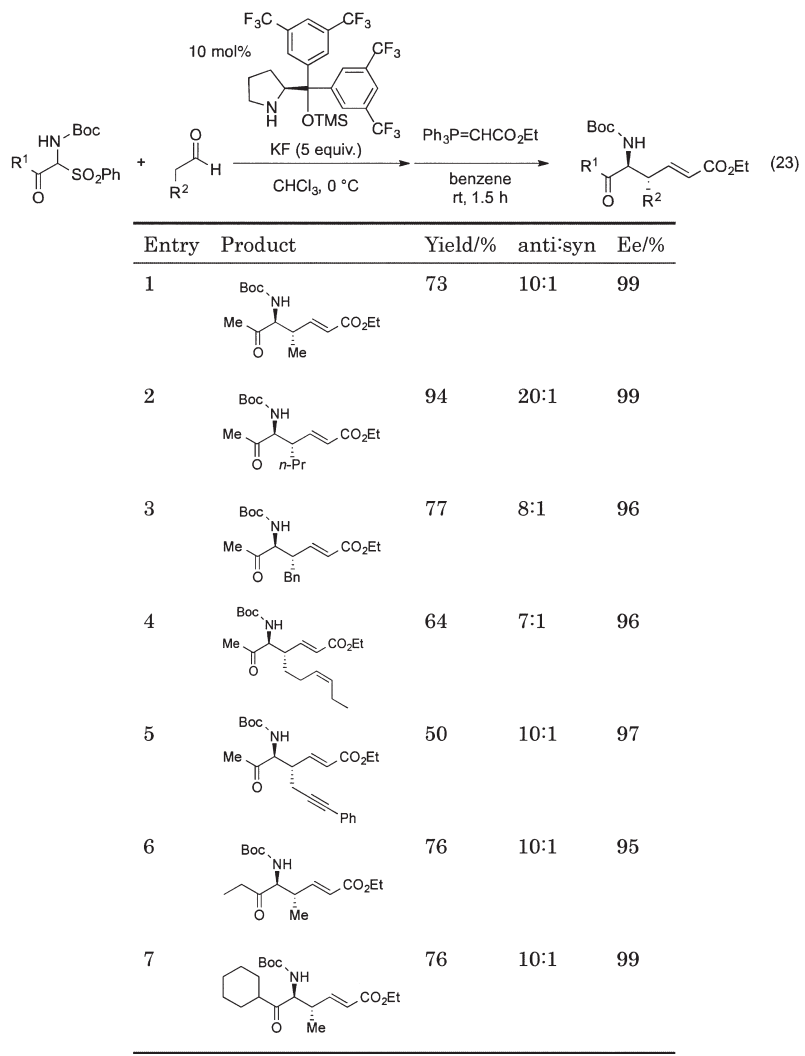

diarylprolinol silyl ether to provide the desired product in good yield with excellent enantioselectivity (eq. 22). This reaction has wide generality (Table 6). Not only propanal, but also other alkyl aldehydes gave good yields with excellent antiselectivity and enantioselectivity. Double-bonds and triplebonds in the side chain of the nucleophilic aldehydes were found not to interfere with the reaction, and the products were formed with excellent diastereo- and enantioselectivities. Besides the imine derived from pyruvaldehyde, imines derived from 2-oxobutanal and 2-cyclohexyl-2-oxo-etanal are also suitable substrates, and afford the Mannich products in good yield and excellent selectivity.

\section{The Mannich Reaction in the Presence of Water ${ }^{38}$}

We have described the asymmetric Mannich reaction using organic solvent. The development of reactions in the presence of water ${ }^{39}$ without using organic solvents is one of the important topics in current chemistry, because water is an environmentally friendly, safe medium, which avoids the problems of pollution that are inherent with organic solvents. ${ }^{40}$ When we started to investigate the Mannich reaction in the presence of water, there were already several aqueous non-enantioselective Mannich reactions of silyl enol ethers, ${ }^{41}$ but only one asymmetric catalytic reaction in the presence of water catalyzed by an organometallic reagent: Kobayashi and coworkers reported the asymmetric Mannich-type reaction of acylhydrazone and silyl enol ether in aqueous organic solvent using a diamine$\mathrm{ZnF}_{2}$-surfactant system. ${ }^{42}$

As for the aldol reaction, Barbas' group ${ }^{43}$ and ours ${ }^{44-46}$ independently developed asymmetric aldol reactions catalyzed by organocatalysts in the presence of water. While Barbas and

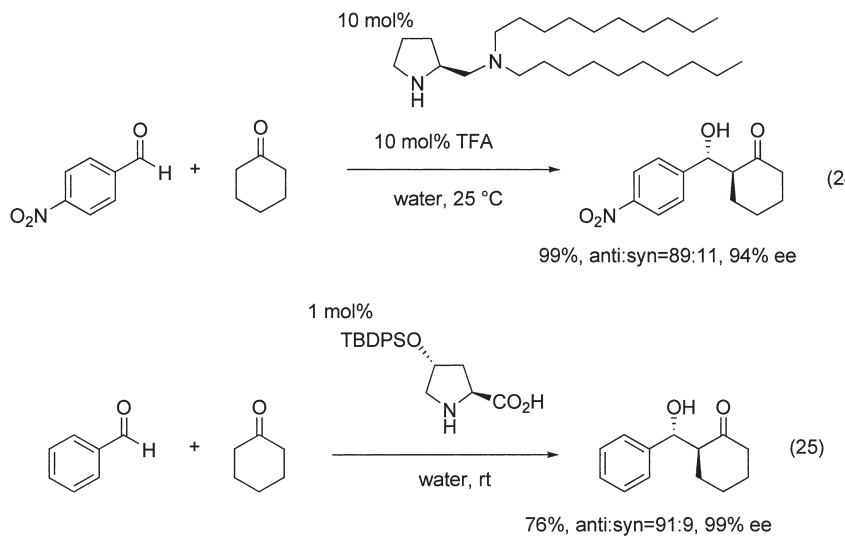




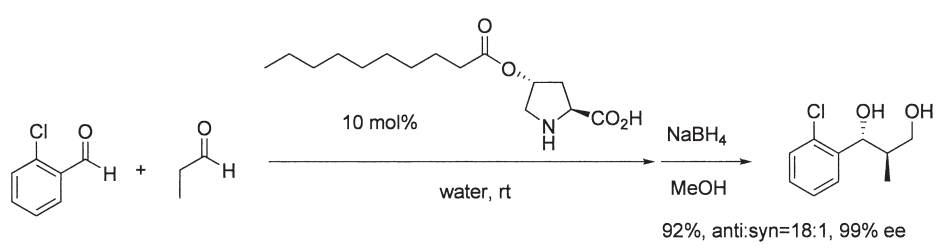

coworkers used a diamine with a long alkyl chain in the presence of acid (eq. 24), ${ }^{43}$ we employed highly hydrophobic siloxyproline (eq. 25) ${ }^{44}$ for the aldol reaction between aldehyde and ketone. We also developed a combined proline-surfactant organocatalyst, which is effective for the cross aldol reaction of two different aldehydes (eq. 26). ${ }^{45}$ Following these reports, several organocatalysts have been developed for the enantioselective aldol reaction in the presence of water. While there are several Mannich reactions which proceed in a mixture of organic solvent and water, ${ }^{47}$ there has been just one other report as far as we are aware that uses only water as the solvent: a threonine-derived organocatalyst was applied to the Mannich reaction in the presence of water, in which alkoxyacetone was the only nucleophile investigated. ${ }^{48}$

We investigated the three-component Mannich reaction of dimethoxyacetaldehyde, $p$-anisidine and cyclohexanone as a model because dimethoxyacetaldehyde is commercially available as its aqueous solution, and this reaction must be per-

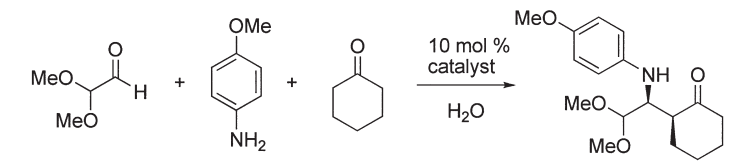

$\begin{array}{llllll} & & & \end{array}$

Table 7. The Mannich reaction of dimethoxyacetaldehyde in the presence of water.

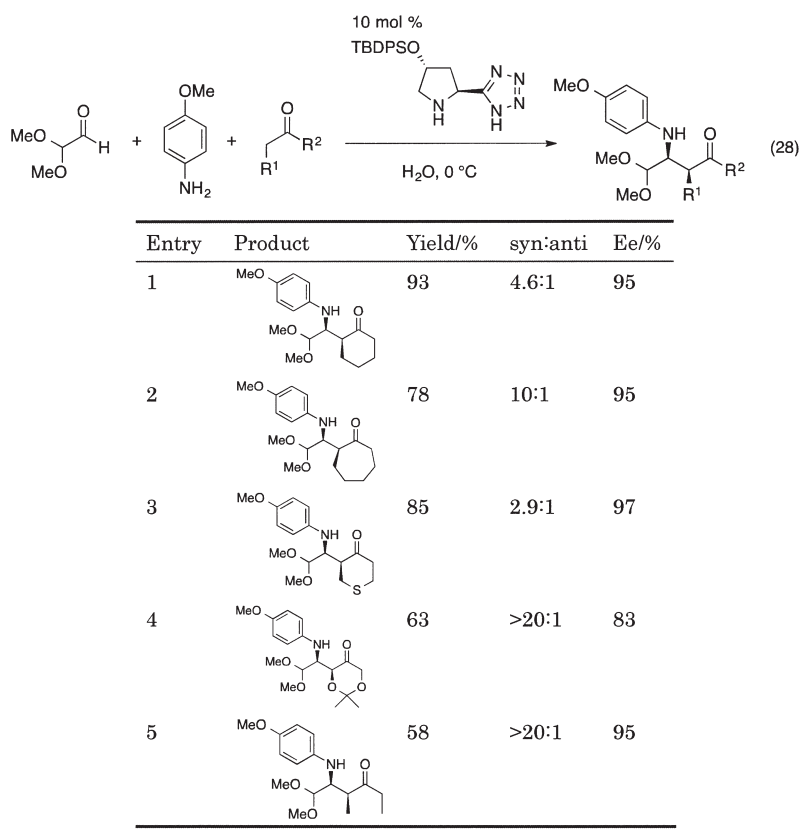

(26)

formed in the presence of water. Moreover, the Mannich product obtained is a synthetically useful poly-functionalized compound. Proline is not an effective catalyst and tetrazole-substituted pyrrolidine as developed independently by Ley, ${ }^{49}$ Yamamoto $^{50}$ and Arvidosson, ${ }^{51}$ is also not suitable. However, a siloxy-tetrazole hybrid catalyst afforded the Mannich product not only in excellent yield but also with very high enantioselectivity. The reaction also proceeds in good yield with excellent enantioselectivity in the presence of a large excess amount (100 equiv) of water. For practicality the amount of water should be reduced, and the reaction was also found to proceed efficiently without the additional amount of water.

The reaction has generality (Table 7): Both cyclohexanone and cycloheptanone are suitable nucleophiles affording the Mannich adduct with high diastereoselectivity and enantioselectivity. 2,2-Dimethyl-1,3-dioxa-5-one can also be employed successfully as the nucleophilic ketone, affording a polyoxyamine derivative which is an important synthetic intermediate for aminosugars with high enantioselectivity. ${ }^{52}$ Acyclic ketones such as 3-pentanone are also suitable nucleophiles.

After this finding, we also investigated the Mannich reaction in the presence of water and found the domino reaction consisting of the desulfonylative preparation of $N$-Ts imine and then enantioselective Mannich reaction can proceed in the presence of water without organic solvent to afford the Mannich product with excellent enantioselectivity, which I already mentioned in the previous section (Section 8). ${ }^{32}$

\section{Conclusion}

We have developed several versions of the asymmetric Mannich reaction catalyzed by organocatalyst. First, we applied the high pressure induced by water-freezing to the proline-mediated three component Mannich reaction of aldehyde, ketone and $p$-anisidine to provide the product in good yield with excellent enantioselectivity due to the effects of both the high pressure and low temperature. During the application of high pressure to other reactions, we found that the crossMannich reaction of two different aldehydes proceeds under ambient pressure with excellent enantioselectivity, which was the beginning of our engagement with organocatalysis. The higher reactivity of aldimine compared to aldehyde in the proline-mediated Mannich and aldol reaction can be explained based on the effective protonation by acid of the aldimine basic nitrogen. The usefulness of this Mannich reaction was demonstrated by the stereoselective synthesis of the $N$-terminal amino acid moiety of Nikkomycin B and Bx. Diarylprolinol silyl ether containing a trifluoromethyl group is an effective organocatalyst of the Mannich reaction of acetaldehyde as the Mannich donor, Mannich reaction of imines derived from aliphatic aldehyde, and Mannich reaction of $\alpha$-keto imine. This catalyst is also suitable for the uninterrupted sequential synthesis of aziridines, in which the key step is the diarylprolinol silyl ether mediated Mannich reaction of the $N$-tosyl imine of chloroacetaldehyde. We also developed an environmentally friendly Mannich reaction in the presence of water, in which only water was employed as the reaction medium without any organic solvent. All the Mannich products are obtained with excellent enantioselectivity, and the reaction conditions are simple without special precautions to exclude moisture and 
oxygen. The catalysts are inexpensive. Thus, we believe the methods described in the present manuscript will be useful for the production of nitrogen-containing natural products and drugs.

\section{Acknowledgement}

I would deeply acknowledge my co-workers, Drs M. Shoji, and H. Ishikawa, Mrs W. Tsuboi, K. Nishimura, K. Okado, I. Ashimine, T. Urushima, M. Shin, T. Okano, T. Itoh, M. Okubo, D. Sakamoto, K. Torii, and H. Shomura, for their outstanding contributions to this work. Dr. Tadafumi Uchimaru is greatly acknowledged for the support in calculation. This work was supported by a Grant-in-Aid for Scientific Research on Innovative Areas "Advanced Molecular Transformations by Organocatalysts" from The Ministry of Education, Culture, Sports, Science and Technology, Japan

\section{References}

1) Selected reviews on organocatalysis: (a) Enantioselective Organocatalysis (Ed.: Dalko, P. I.), Wiley-VCH, Weinheim 2007. (b) Mukherjee, S.; Yang, J. W.; Hoffmann, S.; List, B. Chem. Rev. 2007, 107, 5471. (c) Walji, A. M.; MacMillan, D. W. C. Synlett 2007, 1477. (d) MacMillan, D. W. C. Nature 2008, 455, 304. (e) Barbas III, C. F. Angew. Chem. Int. Ed. 2008, 47, 42. (f) Dondoni, A.; Massi, A. Angew. Chem. Int. Ed. 2008, 47, 4638. (g) Melchiorre, P.; Marigo, M.; Carlone, A.; Bartoli, G. Angew. Chem. Int. Ed. 2008, 47, 6138. (h) Bertelsen, K.; Jørgensen, A. Chem. Soc. Rev. 2009, 38, 2178. (i) Marques-Lopez, E.; Herrera, R. P.; Christmann, M. Nat. Prod. Rep. 2010, 27, 1138. (j) Science of Synthesis, Asymmetric Organocatalysis 1; Lewis Base and Acid Catalysts (Ed.: List, B.), Georg Thieme Verlag KG, Stuttgart, 2012. (k) Science of Synthesis, Asymmetric Organocatalysis 2; Brønsted Base and Acid Catalysts, and Additional Topics (Ed.: Maruoka, K.), Georg Thieme Verlag KG, Stuttgart, 2012 (1) Comprehensive Enantioselective Organocatalysis, Vol. 1, 2, 3 (Ed.: Dalko, P. I.), Wiley-VCH Verlag GmbH \& Co., Weinheim, Germany, 2013.

2) List, B.; Lerner, R. A.; Barbas III, C. F. J. Am. Chem. Soc. 2000, 122, 2395.

3) (a) Kobayashi, S.; Ishitani, H. Chem. Rev. 1999, 99, 1069. (b) Denmark, S. E.; Nicaise, O. J.-C. In Comprehensive Asymmetric Catalysis (Ed.: Jacobsen, E. N.), Springer, Berlin, 1999; p 923. (c) Arend, M.; Westermann, B.; Risch, N. Angew. Chem. Int. Ed. 1998, 37, 1044. (d) Kleinman, E. F. In Comprehensive Organic Synthesis (Ed: Trost, B. M.), Pergamon Press: Oxford, 1991; Chapter 2.3, Vol. 2, p 893. (e) Córdova, A. Acc. Chem. Res. 2004, 37, 102. (f) Notz, W.; Tanaka, F.; Barbas III, C. F. Acc. Chem. Res. 2004, 37, 580. (g) Marques, M. M. B. Angew. Chem. Int. Ed. 2006, 45, 348. (h) Ting, A.; Schaus, S. E. Eur. J. Org. Chem. 2007, 5797. (i) Mukherjee, S.; Yang, J. W.; Hoffmann, S.; List. B. Chem. Rev. 2007, 107, 5471. (j) Benohoud, M; Hayashi, Y. Enamine Catalysis of Mannich Reactions in Science of Synthesis, Asymmetric Organocatalysis 1; Lewis Base and Acid Catalysts (Ed.: List, B.), Georg Thieme Verlag KG, Stuttgart, 2012, pp 73-134. (k) Karimi, B.; Enders, D.; Jafari, E. Synthesis 2013, 45, 2769. (1) Akiyama. T. In Comprehensive Organic Synthesis; Second edition (Eds.: Knochel, P.; Molander, G. A.), Elsevier Ltd.: Oxford, 2014; Chapter 2.16, Vol. 2, pp 629-681.

4) (a) Fujieda, H.; Kanai, M.; Kambara, T.; Iida, A.; Tomioka, K. J. Am. Chem. Soc. 1997, 119, 2060. (b) Ishitani, H.; Ueno, M.; Kobayashi, S. J. Am. Chem. Soc. 1997, 119, 7153. (c) Kobayashi, S.; Ishitani, H.; Ueno, M. J. Am. Chem. Soc. 1998, 120, 431. (d) Ishitani, H.; Ueno, M.; Kobayashi, S. J. Am. Chem. Soc. 2000, 122, 8180. (e) Kobayashi, S.; Kobayashi, J.; Ishitani, H.; Ueno, M. Chem. Eur. J. 2002, 8, 4185. (f) Hagiwara, E.; Fujii, A.; Sodeoka, M. J. Am. Chem. Soc. 1998, 120, 2474. (g) Fujii, A.; Hagiwara, E.; Sodeoka, M. J. Am. Chem. Soc. 1999, 121, 5450. (h) Ferraris, D.; Young, B.; Dudding, T.; Lectka, T. J. Am. Chem. Soc. 1998, 120, 4548. (i) Ferraris, D.; Young, B.; Cox, C.; Drury III, W. J.; Dudding, T.; Lectka, T. J. Org. Chem. 1998, 63, 6090. (j) Ferraris, D.; Dudding, T.; Young, B.; Drury III, W. J.; Lectka, T. J. Org. Chem. 1999, 64, 2168. (k) Ferraris, D.; Young, B.; Cox, C.; Dudding, T.; Drury III, W. J.; Ryzhkov, L.; Taggi, A. E.; Lectka, T. J. Am. Chem. Soc. 2002, 124, 67.

5) (a) Matsunaga, S.; Kumagai, N.; Harada, S.; Shibasaki, M. J. Am. Chem. Soc. 2003, 125, 4712. (b) Yamasaki, S.; Iida, T.; Shibasaki, M.
Tetrahedron Lett. 1999, 40, 307. (c) Yamasaki, S.; Iida, T.; Shibasaki, M. Tetrahedron 1999, 55, 8857 .

6) Juhl, K.; Gathergood, N.; Jørgensen, K. A. Angew. Chem. Int. Ed. 2001, 40, 2995.

7) Trost, B. M.; Terrell, L. R. J. Am. Chem. Soc. 2003, 125, 338.

8) List, B. J. Am. Chem. Soc. 2000, 122, 9336.

9) (a) Córdova, A.; Notz, W.; Zhong, G.; Betancort, J. M.; Barbas III, C. F. J. Am. Chem. Soc. 2002, 124, 1842. (b) Córdova, A.; Watanabe, S.; Tanaka, F.; Notz, W.; Barbas III, C. F. J. Am. Chem. Soc. 2002, 124, 1866.

10) Review, see: (a) Matsumoto, K.; Kaneko, M.; Katsura, H.; Hayashi, N.; Uchida, T.; Acheson, R. M. Heterocycles 1998, 47, 1135. (b) Ciobanu, M.; Matsumoto, K. Liebigs Ann. Recl. 1997, 623. (c) Matsumoto, K.; Sera, A.; Uchida, T. Synthesis 1985, 1. (d) Matsumoto, K.; Sera, A. Synthesis 1985, 999. (e) Jenner, G. Tetrahedron 2002, 58, 5185. (f) Jenner, G. Tetrahedron 1997, 53, 2669. (g) Jenner, G. J. Phys. Org. Chem. 2002, 15, 1. (h) High-Pressure Chemistry (Eds.: van Eldik, R.; Klarner, F.-G.), Wiley-VCH: Weinheim, 2002.

11) Hayakawa, K.; Ueno, Y.; Kawamura, S.; Kato, T.; Hayashi, R. Appl. Microbiol. Biotechnol 1998, 50, 415.

12) Hayashi, Y.; Tsuboi, W.; Shoji, M.; Suzuki, N. Tetrahedron Lett. 2004, $45,4353$.

13) Hayashi, Y; Nishimura, K. Chem. Lett. 2002, 296

14) Hayashi, Y.; Okado, K.; Ashimine, I.; Shoji, M. Tetrahedron Lett. 2002, 43, 8683 .

15) Hayashi, Y.; Tsuboi, W.; Shoji, M.; Suzuki, N. J. Am. Chem. Soc. 2003, 125, 11208 .

16) (a) Hayashi, Y.; Tsuboi, W.; Ashimine, I.; Urushima, T.; Shoji, M.; Sakai, K. Angew. Chem. Int. Ed. 2003, 42, 3677. (b) Hayashi, Y.; Urushima, T.; Tsuboi, W.; Shoji, M. Nat. Protocols 2007, 2, 113.

17) (a) Córdova, A. Synlett 2003, 1651. (b) Córdova, A. Chem. Eur. J. 2004, 10, 1987.

18) Hayashi, Y.; Urushima, T.; Shoji, M.; Uchimaru, T.; Shiina, I. Adv. Synth. Catal. 2005, 347, 1595.

19) Northrup, A. B.; MacMillan, D. W. C. J. Am. Chem. Soc. 2002, 124, 6798.

20) Hayashi, Y.; Urushima, T.; Shin. M; Shoji, M. Tetrahedron 2005, 61, 11393.

21) (a) Dahn, U.; Hagenmaier, H.; Hohne, M.; Konig, W. A.; Wolf, G.; Zahner, H. Arch. Microbiol. 1976, 107, 143. (b) Hagenmaier, H.; Keckeisen, A.; Zahner, H.; Konig, W. A. Liebigs Ann. Chem. 1979, 1494. (c) Konig, W. A.; Hass, W.; Dehler, W.; Fiedler, H. P.; Zahner, H. Liebigs Ann. Chem. 1980, 622. (d) Hagenmaier, H.; Keckeisen, A.; Dehler, W.; Fiedler, H. P.; Zahner, H.; Konig, W. A. Liebigs Ann. Chem. 1981, 1018.

22) (a) Kobinata, K.; Uramoto, M.; Nishii, M.; Kusakabe, H.; Nakamura, G.; Isono, K. Agric. Biol. Chem. 1980, 44, 1709. (b) Uramoto, M.; Kobinata, K.; Isono, K.; Higashijima, T.; Miyazawa, T.; Jenkins, E. E.; McCloskey, J. A. Tetrahedron Lett. 1980, 21, 3395. (c) Uramoto, M.; Kobinata, K.; Isono, K.; Higashijima, T.; Miyazawa, T.; Jenkins, E. E.; McCloskey, J. A. Tetrahedron 1982, 38, 1599.

23) (a) Currie, G. S.; Drew, M. G. B.; Harwood, L. M.; Hughes, D. J Luke, R. W. A.; Vickers, R. J. J. Chem. Soc., Perkin Trans. 12000 , 2982. (b) Carlsen, P. H. J.; Katsuki, T.; Martin, V. S.; Sharpless, K. B. J. Org. Chem. 1981, 46, 3936.

24) Hayashi, Y.; Okano, T.; Itoh, T.; Urushima, T.; Ishikawa, H.; Uchimaru, T. Angew. Chem. Int. Ed. 2008, 47, 9053.

25) (a) Denmark, S. E.; Bui, T. J. Org. Chem. 2005, 70, 10190. (b) Boxer M. B.; Yamamoto, H. J. Am. Chem. Soc. 2006, 128, 48.

26) (a) Hayashi, Y.; Itoh, T.; Aratake, S.; Ishikawa, H. Angew. Chem. Int. Ed. 2008, 47, 2082. (b) Hayashi, Y.; Samanta, S.; Itoh, T.; Ishikawa, H Org. Lett. 2008, 10, 5581.

27) Yang, J. W.; Chandler, C.; Stadler, M.; Kampen, D.; List, B. Nature 2008, 452, 453 .

28) Hayashi, Y.; Itoh, T.; Ohkubo, M.; Ishikawa, H. Angew. Chem. Int. Ed. 2008, 47, 4722 .

29) García-García, P.; Ladépêche, A.; Halder, R.; List, B. Angew. Chem. Int. Ed. 2008, 47, 4719.

30) Hayashi, Y.; Gotoh, H.; Hayashi, T.; Shoji, M. Angew. Chem. Int. Ed. 2005, 44, 4212

31) (a) Marigo, M.; Wabnitz, T. C.; Fielenbach, D.; Jørgensen, K. A. Angew. Chem. Int. Ed. 2005, 44, 794. (b) Marigo, M.; Fielenbach, D.; Braunton, A.; Kjasgaard, A.; Jørgensen, K. A. Angew. Chem. Int. Ed. $\mathbf{2 0 0 5}, 44,3703$.

32) Urushima, T.; Ishikawa, H.; Hayashi, Y. Chem. Eur. J. 2011, 17, 8273.

33) (a) Gianelli, C.; Sambri, L.; Carlone, A.; Bartoli, G.; Melchiorre, P. 
Angew. Chem. Int. Ed. 2008, 47, 8700. (b) Deiana, L.; Zhao, G.-L.; Dziedzic, P.; Rios, R.; Vesely, J.; Ekstrom, J.; Córdova, A. Tetrahedron Lett. 2010, 51, 234. (c) Gomez-Bengoa, E.; Maestro, M.; Mielgo, A.; Otazo, I.; Palomo, C.; Velilla, I. Chem. Eur. J. 2010, 16, 5333. (d) Galzerano, P.; Agostino, D.; Bencivenni, G.; Sambri, L.; Bartoli, G.; Melchiorre, P. Chem. Eur. J. 2010, 16, 6069.

34) (a) Reviews, see: Kan, T.; Fukuyama, T. J. Synth. Org. Chem., Jpn. 2001, 59, 779. (b) Kan, T.; Fukuyama, T. Chem. Commun. 2004, 353.

35) Hayashi, Y.; Urushima, T.; Sakamoto, D.: Torii, K.; Ishikawa, H. Eur. J. Chem. 2011, 17, 11715.

36) Hayashi, Y,; Yasui, Y.; Kawamura, T.; Kojima, M.; Ishikawa, H. Angew. Chem. Int. Ed. 2011, 50, 2804.

37) Hayashi, Y.; Sakamoto, D.; Shomura, H.; Hashizume, D. Chem. Eur. J. 2013, 19, 7678 .

38) Hayashi, Y.; Urushima, T.; Aratake, S.; Okano, T.; Obi, K. Org. Lett. 2008, 10, 21 .

39) (a) Hayashi, Y. Angew. Chem. Int. Ed. 2006, 45, 8103. (b) Brogan, A, P.; Dickerson, T, J.; Janda, K. D. Angew. Chem. Int. Ed. 2006, 45, 8100 .

40) (a) Organic Synthesis in Water (Ed.: Grieco, P. A.), Blackie A \& P: London, 1998. (b) Lindström, U. M. Chem. Rev. 2002, 102, 2751. (c) Blackmond, D, G.; Armstrong, A.; Coombe, V.; Wells, A. Angew. Chem. Int. Ed. 2007, 46, 3798. (d) Organic Reactions in Water (Ed. Lindström, U. M.), Blackwell Publishing: Oxford, 2007. (e) Ray, M.; Singh, V. K. Chem. Commun. 2009, 44, 6687. (f) Mase, N.; Barbas III, C. F. Org. Biomol. Chem. 2010, 8, 4043. (g) Science of Synthesis, Water in Organic Synthesis (Ed.: Kobayashi, S.), Georg Thieme Verlag KG, Stuttgart, 2012. (h) Mlynarski, J.; Bas, S. Chem. Soc. Rev. 2014, $43,577$.

41) Aqueous Mannich reaction of silyl enol ether, see; (a) Loh, T, P.; Wei, L. L. Tetrahedron Lett. 1998, 39, 323. (b) Manabe, K.; Kobayashi, S. Org. Lett. 1999, 1, 1965. (c) Akiyama, T.; Takaya, J.; Kagoshima, H. Synlett 1999, 1426. (d) Manabe, K.; Mori, Y.; Kobayashi, S. Tetrahedron 2001, 57, 2537. (e) Akiyama, T.; Itoh, J.; Fuchibe, K. Synlett 2002, 1269.

42) (a) Hamada, T.; Manabe, K.; Kobayashi, S. J. Am. Chem. Soc. 2004, 126, 7768. (b) Hamada, T.; Manabe, K.; Kobayashi, S. Chem. Eur. J. 2006, 12, 1205 .

43) Mase, N.; Nakai, Y.; Ohara, N.; Yoda, H.; Takabe, K.; Tanaka, F.; Barbas III, C. F. J. Am. Chem. Soc. 2006, 128, 734.

44) (a) Hayashi, Y.; Sumiya, T.; Takahashi, J.; Gotoh, H.; Urushima, T.; Shoji, M. Angew. Chem. Int. Ed. 2006, 45, 958. (b) Aratake, S.; Itoh, T.; Okano, T.; Nagae, N.; Sumiya, T.; Shoji, M.; Hayashi, Y. Chem. Eur. J. 2007, 13, 10246 .

45) Hayashi, Y.; Aratake, S.; Okano, T.; Takahashi, J.; Sumiya, T.; Shoji, M. Angew. Chem. Int. Ed. 2006, 45, 5527.

46) (a) Hayashi, Y.; Aratake, S.; Itoh, T.; Okano, T.; Sumiya, T.; Shoji, M. Chem. Commun. 2007, 957. (b) Aratake, S.; Itoh, T.; Okano, T.; Usui, T.; Shoji, M.; Hayashi, Y. Chem. Commun. 2007, 2524.
47) (a) Itoh, T.; Tokoya, M.; Miyauchi, K.; Nagata, K.; Ohsawa, A. Org. Lett. 2003, 5, 4301. (b) An, Y.-J.; Wang, C.-C.; Liu, Z.-P.; Tao, J.-C. Helv. Chim. Acta 2012, 95, 3.

48) Cheng, L.; Wu, X.; Lu, Y. Org. Biomol. Chem. 2007, 5, 1018.

49) Cobb, A. J. A.; Shaw, D. M.; Ley, S. V. Synlett 2004, 558.

50) Torii, H.; Nakadai, M.; Ishihara, K.; Saito, S.; Yamamoto, H. Angew. Chem. Int. Ed. 2004. 43, 1983.

51) Hartikka, A.; Arvidosson, P. I. Tetrahedron: Asymmetry 2004, 15, 1831.

52) (a) Westermann, B.; Neuhaus, C. Angew. Chem. Int. Ed. 2005, 44, 4077. (b) Enders, D.; Grondal, C.; Vrettou, M.; Raabe, G. Angew. Chem. Int. Ed. 2005, 44, 4079

\section{PROFILE}

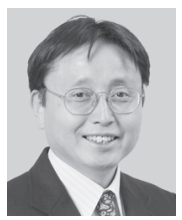

Yujiro Hayashi was born in 1962 in Gunma, and received his B.Sc. (1984), M.Sc. (1986) (Prof. T. Mukaiyama) and a Ph.D. degree (1992, Prof. K. Narasaka) from The University of Tokyo. He was appointed as an assistant professor at The University of Tokyo (1987). He moved to Tokyo University of Science as an associate professor (1998), was promoted to full professor (2006), and moved to Tohoku University (2012). He undertook postdoctoral study at Harvard University (Prof. E. J. Corey, 1994-1996). He was awarded with an Incentive Award in Synthetic Organic Chemistry, Japan (1998), SSOCJ Daiichi-Sankyo Award for Medicinal Organic Chemistry (2008) and the Chemical Society of Japan Award for Creative Work for 2010. He was selected as a lecturer of the Oppolzer Lectures at University of Geneva (2011), and he received a Novartis Chemistry Lectureship Award (2011/2012) and Inoue Prize for Science (2012). He is an associate editor of Chemistry Letters (2010-present). His current interests are mainly in the development of new synthetic reactions in the field of organocatalysis, and the total synthesis of biologically active natural products. 